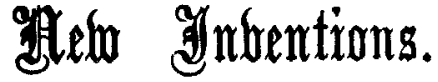

\section{THE NEW FINSEN-REYN LAMP.}

WHEN attending Professor Finsen's Institute in Copenhagen I found the authorities there hard at work experimenting with a new lamp that had been devised by Professor Finsen and one of his colleagues, Dr. Reyn, and after a thorough, thus insuring privacy in the treatment of each individual case a point of considerable importance in England. The lamp consists of three parts - namely, the arc light, the concentration apparatus or telescope, and the compressor, the two latter being connected with a water circulating system for cooling purposes. The lamp and telescope are placed at either end of a connecting rod which in turn is mounted on a moveable stand provided with a universal movement mechanism at its upper end. The arc lamp is for a direct

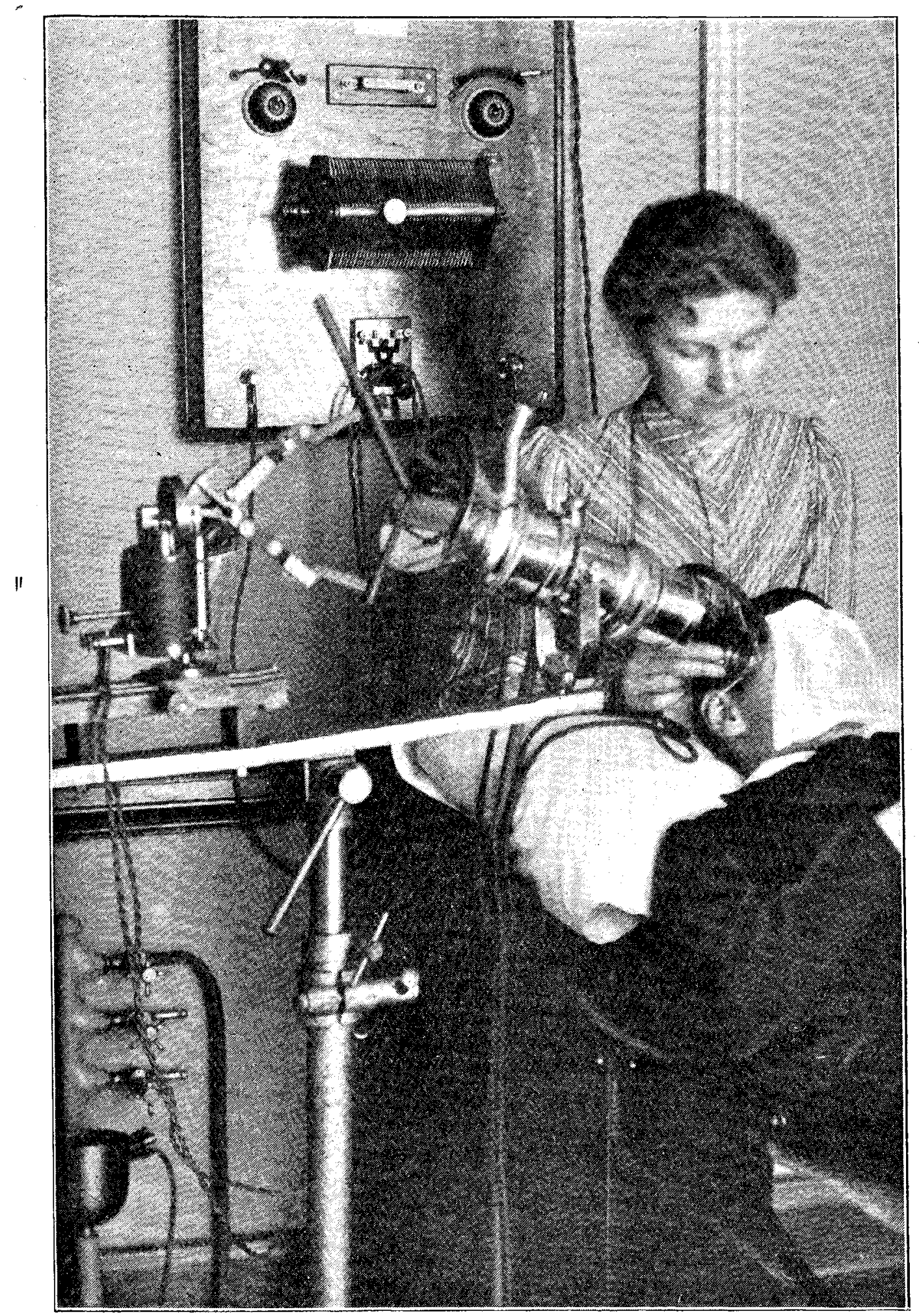

The Fusen-Reyn lamp at work.

prolonged, and satisfactory trial, botl in the laboratory and current of 55 volts and 20 ampères and the carbons, which the institute, this lamp has now been issued with the are automatically fed, incline at an angle directing the guarantee and authority of the Institute. The first of these rays on to the concentration apparatus. It is mounted on lamps sent out from Copenhagen has arrived in this country a pin to which it can be fastened at the necessary height and is shown in the accompanying illustration. The prin- by a screw, and this in turn is attached to a rack-andciple on which the lamp is constructed is entirely that of pinion arranged on tile connecting rod giving a forthe older and larger Finsen lamp, but one patient only ward and backward movement, so that the lamp may be can be treated at a time instead of four as with the latter, placed at any required distance from the telescope. The 
concentration apparatus is much shorter than in the old Finsen lamp, being only ten inches in length and therefore easily manipulated. Near the centre it is swung on a U-shaped rest, allowing the extremities an up-and-down movement, but it can be fixed by a screw clamp when adjusted in the required position. Three lenses of rock crystal, each eight centimetres in diameter, are fixed at intervals in the telescope, the upper one being made up of three parts. fitted together to give greater concentration. Between the txo lower lenses is a chamber filled with distilled water when the lamp is in use and which is changed daily. At the upper end of the telescope a cap, specially devised by Dr. Reyn, is placed, formed of two more rock crystal lenses holding distilled water between them and having round the frame in which they are set a hollow tube in which cold water, carried by a rubber tube from a tap, circulates. This keeps the distilled water from becoming too hot and protects the lenses, enabling them to stand the arc light in the closest proximity without breaking, as so frequently happens with the older lamp. Many more rays are in this way concentrated and these are directed through a water-cooled compressor held by a nurse on to the part to be treated as in the old system. A metal hood fitted to the cap protects the operator from the rays of the arc. The compressors are the same in size and shape as those used with the old lamp. The water circulating in the cap of the telescope is conveyed by a small rubber tube to the compressor and then discharged into an open cup fitted to a waste pipe, so that the operator can always be sure it is circulating properly. Two parts are therefore supplied with running water and two parts with stationary distilled water. As regards the treatment, each séance lasts one and a quarter hours, though a reaction is obtained from a much shorter exposure. In the treatment by other smaller lamps burning from five to 15 ampères, sittings lasting for periods from ten to 15 minutes have been adopted, but these do not, in Professor Finsen's opinion, obtain a sufficiently deep peretration and reaction to give a permanent result. I am informed that the concentration and penetration of the rays given by the new lamp are greater than from the old one, that results have been achieved more rapidly, and that they are so far of a very satisfactory character. Its cost is less in proportion when compared with the old Finsen lamp with its four telescopes; and other advantages of the present lamp will be fonnd in (1) the lessened cost of current consumed for each patient; (2) the apparently greater rapidity in obtaining satisfactory results: (3) the fact that each patient can be treated separately and privately ; (4) its mobility, limited only by the length of its electrical and water-conveying connexions; and (5) the fact that it affords greater facility for treating any part of the body than do some lamps now in use. Further advantages may show themselves later; and knowing the patient investigation that every detail receives in Professor Finsen's laboratory it is probable that the satisfactory results already obtained with this lamp in cases of lupus vulgaris will prove as permanent as the large majority of those treated by the old apparatus, but this time alone can decide.

George H. Graham. M. D. Durh.

Ohi Caventish-street, W.

\section{A NON-LEAKABLE FOUNTAIN PEN.}

WE have received from the Moore's Non-leakable Fountain Pen Company of 23, Fore-street Avenue, London, E.C., specimens of their fountain pens and have given them trial before reporting upon them. As a result we can speak with conviction as to their merits. They are strong and simple of mechanism. They can be easily refilled and without necessity to soil the fingers, while they can be taken to any pieces acco ding to the furnished instructions with no trouble whatever. By an arrangement that is we believe quite new, the cap can be replaced over the nib in such a way as both to protect the nib and to close the ink reservoir. As a consequence the pen can be carried in any position without the risk of leaking; the only thing that the user of the pen has to bear in mind is that when the cap is taken off the reservoir is open and is only closed by pushing the pen up into writing position. If this point is always remembered there should be no risk of spilling the ink. We have tried these pens, the prices of which range from $12 s .6 d$. to $20 s$. 6d., with both fine and broad nibs, and have found each thoroughly satisfactory.

\section{Looking JBack.}

\section{FROM}

THE LANCET, SATURDAY, FEB. 12, 1825.

\section{REVIEW. 1}

Elements of Medical Jurisprudence. By THEODRIC ROMEYN BECK, M.D. \&c. \&c. 8vo. New York; with Notes, and an Appendix, oy WM. DunLor, Member of the Royal College of Surgeons, \&c. 8vo. pp. 640. London, 1825. Anderson.

Mental alienation.-The following method of discriminating between feigned and real insanity is new to us, and no doubt also to many of our readers.

"The best mode that has yet been discovered for forcing a man who feigns madness to confess and desist, is by the use of the whirling chair, that is, a chair placed upon a spindle which revolves upon its own axis, and is turned by a wheel and crank, with the rapidity of the fly of a jack; it produces nausea even to syncope, and after two minutes of such discipline, few men can command spirits sufficient to act any part. It was by this means that M'Dougal, of Glasgow, was rendered sane when he feigned madness, to avoid being tried for sinking ships, to defraud the underwriters-but he betrayed himself to the medical men by the common fault of impostors, not having ' a method in his madness,' but mixing ap the two irreconcilable characters of

"The moping idiot, and the madman gay.'"

Persons found dead.-In this chapter the author has brought together most of the opinions that have been advanced on the subject, and much of the contradictory testimony likely to arise in questions of this nature. Respect. ing the necessity of a general examination of the body of a person found dead, a curious opinion of a northern professor is quoted by the Editor.

“'When,' said he, in his lectures, 'you find any appearance sufficient to account for death, rest satisfied with that, and inquire no further; as further examination will only tend to embarrass your evidence, and render it contradictory.' We have all heard of a worthy country justice, who made it a rule never to hear both sides of a question, because, when he only heard one, he could decide without hesitation ; but hearing both only puzzled him."

In other words, do not proceed too far, or your testimony may be less positive when called upon to give your opinion in a court of justice-which puts us in mind of an oration delivered last year by Dr. Gordon Smith, at a medical society, in which, among other matters, be proposed, that " in order to avoid any appearance of ignorance in a court of justice, a consultation of the medical witnesses should be previously obtained for the purpose of deciding on the nature of the evidence to be given," which is, in other words, for the purpose of deciding whether an unfortunate prisoner should have a fair trial or not, or whether he should be convicted of the crime charged to him, if innocent, or altogether elude justice if guilty-and this for the purpose of "avoiding the appearance of ignorance in a court of justice."

The notes of the editor are frequently curious and valuable, and the whole production is, in our opinion, decidedly superior to any other that has yet appeared on the subject of medical jurisprudence.

1 A portion only has been transcribed.

Freemasonry.-Tahere Lodge, No. 2546.-A meeting of this Lodge was held at Frascati's Restaurant, Oxford-street, W., on Tuesday, Feb. 10th, W. Bro. G. H. R. Holden, M.D., W.M., being in the chair.-Bro. M. Dale Wood, M.D., was admitted to the third degree, while Dr. W. Jobson Horne was initiated into Freemasonry. A grant of a guinea to Our Brother's Bed in the Home for the Dying was voted unanimously. It was announced that the promotion of the William Harvey Chapter had been taken over by the Sancta Maria Lodge. A considerable number of brethren subsequently dined trgether. 